\title{
Industry's neglect of prescribing information for children
}

$\mathrm{P}$ hysicians caring for Canadian children are frequently denied easy access to important prescribing information. The reason? The pharmaceutical industry generally has not submitted evidence in its possession supporting safe pediatric doses and dosing intervals to Health Canada. As a result, the Compendium of Pharmaceuticals and Specialties (CPS), the most widely used source of prescribing information for primary care providers and pediatricians, is littered with the statement that safety and efficacy have not been established in the pediatric population. The statement is often untrue.

Accurate pediatric prescribing information in all official documents including product inserts, labels on medications, the $C P S$, advertising and, frequently, national guidelines depends on manufacturers to bring forward evidence for a pediatric indication. Once approved, label wording is agreed upon between regulatory authorities such as Health Canada and manufacturers. Thus, even when pediatric data exist, they will only be provided to health professionals in jurisdictions where manufacturers choose to apply for a pediatric indication.

At present, Canadian health professionals do not have the same access to evidence as their American and European colleagues. As a consequence, Canadian children and youth may fall victim to medication errors and mistreatment simply because of limited access to information about pediatric drugs. In addition, without approval for pediatric use, our children may be denied access to expensive new drugs because of lack of insurance coverage. Labelled indications also provide incentives for research and evidence-based reviews by national and provincial formularies.

In fact, a recent query of the US Food and Drug Administration (FDA) website showed that many drugs that have obtained pediatric-specific labelling in the US are described as having "insufficient evidence" in Canada. For example, Celebrex, a medication used in the treatment of juvenile idiopathic arthritis, was approved for this use in 2006. However, the CPS states there is insufficient evidence to support its use in juvenile idiopathic arthritis.

What is even more distressing is that some of the clinical trials used to generate evidence for FDA approval of drugs enrolled Canadian children, and yet the beneficiaries of such studies are only American children. Such opportunistic behaviour and permissive rules allowed Canadian children to be put at risk in regulated trials but denied the benefits of that same research.

Children are not little adults. Pediatric labelling should go well beyond simply adjusting adult doses to a pediatric weight, because this is inappropriate and potentially dangerous. The unanticipated increased suicide risk in pediatric depression resulting from early off-label use of selective serotonin reuptake inhibitors, guided only by data in adults, is a striking example.
Not only is evidence inaccessible, but often critical outcome and dosing studies are lacking. The pharmaceutical industry has argued that pediatric markets are small and not profitable. Without financial incentives and legislation, companies regularly bring drugs to market without studies in children. Physicians caring for children with the same adult condition must then choose to either use the drug off-label or not use it at all. Either option denies children potential benefits simply because of lack of study in children.

Given industry's poor record in carrying out research in children, other jurisdictions, notably the United States and Europe, introduced both incentives and a legislated solution. In 2003, the US Congress passed the Pediatric Research Equity Act that requires drug manufacturers with drugs expected to be used in children to conduct studies and submit results to the US FDA. ${ }^{2}$ The European Parliament passed a regulatory amendment in 2006 with similar requirements. ${ }^{3}$

\section{Clinical trials used to generate evidence for FDA approval of drugs enrolled Canadian children, and yet the beneficiaries of such studies are only American children.}

In both instances, changes in laws and regulations were coupled with strong financial incentives. In the US, the government offered a six-month extension of market exclusivity, both for adults and children. Europe provided financial incentives in the form of a six-month extension of data protection, effectively limiting entry of a generic drug for that period. These financial incentives resulted in more pediatric drug studies followed by a large number of applications for amendment to drug prescribing information to include evidencebased, pediatric indications and dosing.

In 2006, the Government of Canada attempted to remedy the situation by providing a six-month extension for data protection similar to the European market. However, because of our relatively small size (only 3\% of world market share ${ }^{4}$ ), provisions comparable to Europe did not entice many manufacturers to submit the evidence necessary for Canadian pediatric indication and dosing.

This issue goes well beyond Canada and affects children all over the world. For example, Japan and Australia, countries with comparable market sizes to Canada, also lack legislation. Indeed, if a market the size of Europe or the US is 
required for the pharmaceutical industry to disclose their data, Canadians and others worldwide have no hope of having the needed data submitted in these countries. In line with recommendations of the World Health Organization, ${ }^{5}$ we need international harmonization of laws to ensure that appropriate incentives are in place to promote pediatric research necessary for pediatric indications and prescribing information. As well, we need mechanisms to ensure that any available information is shared with all small markets.

It is utterly unacceptable for pharmaceutical manufacturers to profit from risky off-label use of medications in children because they have failed to conduct the studies or have chosen to withhold this important drug safety information from a country's drug regulators. Especially given that it is little more trouble than cutting and pasting an FDA submission on a Health Canada form. Unfortunately, laws seem to be the only way to control such unethical behaviour.

We should ask our politicians to protect Canadian children by enacting strict legislation similar to the US Pediatric Research Equity Act and, as a quick stopgap, get Health Canada to enact strict regulations to address this appalling inequity.

Bob Peterson MD PhD MPH, Paul C. Hébert MD MHSc, Noni MacDonald MD MSc, Daniel Rosenfield BArtsSc, Matthew B. Stanbrook MD PhD, Ken Flegel MDCM MSc
Competing interests: Bob Peterson has received funds for travel from the Center for Innovation in Regulatory Science. He is executive director of the Drug Safety and Effectiveness Network, Canadian Institutes of Health Research. See www.cmaj.ca/misc/cmaj_staff.dtl. None declared by Daniel Rosenfield.

Affiliations: Bob Peterson is Clinical Professor, Department of Paediatrics, Faculty of Medicine, University of British Columbia, Vancouver, BC. See www.cmaj.ca/misc/cmaj_staff.dtl. Daniel Rosenfield is from the Faculty of Medicine, University of Toronto, Toronto, Ont.

Correspondence to: CMAJ editor, pubs@cmaj.ca

\section{References}

1. Bridge JA, Iyengar S, Salary CB, et al. Clinical response and risk for reported suicidal ideation and suicide attempts in pediatric antidepressant treatment: a metaanalysis of randomized controlled trials. JAMA 2007;297:1683-96.

2. Pediatric Research Equity Act, Pub. L. No. 108-155, 117 Stat. 1936 (2003). Available: www.fda.gov/downloads/Drugs/DevelopmentApprovalProcess/Development Resources/UCM049870.pdf (accessed 2011 Apr. 6).

3. Regulation (EC) no. 1901/2006 of the European Parliament and of the Council on Medicinal Products for Pediatric Use, and amending Regulation (EEC) No. 1768/92, Directive 2001/20/EC, Directive 2001/83/EC and Regulation (EC) No. 726/2004 (2006).

4. Life sciences gateway. Canadian pharmaceutical industry profile. Ottawa $(\mathrm{ON})$ : Industry Canada; 2010. Available: www.ic.gc.ca/eic/site/lsg-pdsv.nsf/eng/h_hn00021 .html (accessed 2011 Apr. 6).

5. Better medicines for children. World Health Assembly; 2007 May 14-23; Geneva (CH): World Helath Organization; 2007. Available: www.who.int/gb/ebwha/pdf _files/WHA60/A60_R20-en.pdf (accessed 2011 Apr. 7).

CMAJ 2011. DOI:10.1503/cmaj.110563 